University of Wollongong

Research Online

2020

\title{
A qualitative exploration of SMART Recovery meetings in Australia and the role of a digital platform to support routine outcome monitoring
}

\author{
Rebecca Gray \\ University of New South Wales \\ Peter James Kelly \\ University of Wollongong, pkelly@uow.edu.au \\ Alison Beck \\ University of Wollongong, alisonbe@uow.edu.au \\ Amanda Baker \\ University of Newcastle,Amanda.Baker@newcastle.edu.au \\ Frank P. Deane \\ University of Wollongong, fdeane@uow.edu.au

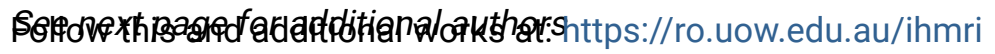 \\ Part of the Medicine and Health Sciences Commons
}

\section{Recommended Citation \\ Gray, Rebecca; Kelly, Peter James; Beck, Alison; Baker, Amanda; Deane, Frank P.; Neale, Joanne; Treloar, Carla; Hides, Leanne; Manning, Victoria; Shakeshaft, Anthony; Kelly, John F.; Argent, Angela; and McGlaughlin, Ryan, "A qualitative exploration of SMART Recovery meetings in Australia and the role of a digital platform to support routine outcome monitoring" (2020). Illawarra Health and Medical Research Institute. 1477. \\ https://ro.uow.edu.au/ihmri/1477}

Research Online is the open access institutional repository for the University of Wollongong. For further information contact the UOW Library: research-pubs@uow.edu.au 


\title{
A qualitative exploration of SMART Recovery meetings in Australia and the role of a digital platform to support routine outcome monitoring
}

\author{
Abstract \\ Previous research has reported on the benefits of mutual support groups. However, such groups do not \\ routinely collect data on participant outcomes. Moreover, the effect of collecting outcomes measures on \\ these groups is unknown. The objective of this mixed methods study was to elicit participant views on \\ using a novel, purpose built digital platform for routine outcome monitoring (ROM) as a standard \\ component of a mutual support group. SMART Recovery, or the Self-Management and Recovery Training \\ program, is group-based and uses professional clinicians to facilitate discussion and foster mutual \\ support for a range of addictive behaviours, alongside Cognitive Behavioural Therapy and Motivational \\ Interviewing techniques. This paper reports on the qualitative component of this study and how \\ participants perceive ROMs, and the potential shift to technological resources. Twenty semi-structured \\ telephone interviews were conducted with participants from SMART Recovery groups across New South \\ Wales, Australia. Participants discussed their use of mutual support within group meetings to manage \\ their recovery, including: naming their goals in front of peers; learning from clinicians and group \\ discussion; and developing reciprocal and caring relationships. They also described any previous \\ experience with routine outcomes measures and how digital technologies might enhance or hinder group \\ function. Participants valued mutual support groups and reported that digital technologies could be \\ complementary to physical, weekly group meetings. They were also concerned that the introduction of \\ technological resources might pose a threat to physical meetings, thereby risking their access to mutual \\ support. Findings have implications for the implementation of ROM when delivered via digital \\ mechanisms, and indicate threats and opportunities that warrant consideration for future initiatives.

\section{Disciplines} \\ Medicine and Health Sciences

\section{Publication Details} \\ Gray, R. M., Kelly, P. J., Beck, A. K., Baker, A. L., Deane, F. P., Neale, J., Treloar, C., Hides, L., Manning, V., \\ Shakeshaft, A., Kelly, J., Argent, A. \& McGlaughlin, R. (2020). A qualitative exploration of SMART Recovery \\ meetings in Australia and the role of a digital platform to support routine outcome monitoring. Addictive \\ Behaviors, 101 106144-1-106144-7.
}

\section{Authors}

Rebecca Gray, Peter James Kelly, Alison Beck, Amanda Baker, Frank P. Deane, Joanne Neale, Carla Treloar, Leanne Hides, Victoria Manning, Anthony Shakeshaft, John F. Kelly, Angela Argent, and Ryan McGlaughlin 
A qualitative exploration of SMART Recovery Meetings in Australia and the role of a Digital Platform to Support Routine Outcome Monitoring

Rebecca M. Gray, PhD, MA, BA (Hons) ${ }^{1}$

Peter J. Kelly, PhD (Clinical Psychology), GradDipAppPsych, BSc ${ }^{2}$

Alison K. Beck, DClin (Psych), BPsych (Hons) ${ }^{2}$

Amanda L. Baker, PhD, MPsych, BA(Hons Psych) ${ }^{3}$

Frank P. Deane, PhD, PGDipClinPsych, MSc, $\mathrm{BSc}^{2}$

Joanne Neale, DPhil, CQSW, MA, BA(Hons $)^{4}$

Carla Treloar, $\mathrm{PhD}, \mathrm{BSc}(\text { Hons })^{1}$

Leanne Hides, $\mathrm{PhD}$, BBehSc(Hons $)^{5}$

Victoria Manning, PhD, MSc, BSc(Hons Psych) ${ }^{6}$

Anthony Shakeshaft, PhD, MA, BA ${ }^{7}$

John Kelly, PhD, BSc(Psych) ${ }^{8}$

Angela Argent, $\mathrm{PhD}, \mathrm{BA}(\text { Hons })^{9}$

Ryan McGlaughlin, PGCert(Comm Mgt)

1. Centre for Social Research in Health, University of New South Wales, Australia

2. Illawarra Health and Medical Research Institute and School of Psychology, Faculty of Social Sciences, University of Wollongong, Australia

3. School of Medicine and Public Health, University of Newcastle, Australia

4. Institute of Psychiatry, Psychology and Neuroscience, King's College London, UK

5. Centre for Youth Substance Abuse Research, Lives Lived Well Group, School of Psychology, University of Queensland, Australia 
6. Eastern Health Clinical School, Faculty of Medicine, Nursing and Health Sciences, Monash University, Australia

7. National Drug and Alcohol Research Centre, University of New South Wales, Australia

8. Harvard Medical School, Harvard University, USA

9. SMART Recovery Australia, Sydney, Australia

Corresponding Author:

Rebecca Gray z3195169@unsw.edu.au 


\section{Abstract}

Previous research has reported on the benefits of mutual support groups. However, such groups do not routinely collect data on participant outcomes. Moreover, the effect of collecting outcomes measures on these groups is unknown. The objective of this mixed methods study was to elicit participant views on using a novel, purpose built digital platform for routine outcome monitoring (ROM) as a standard component of a mutual support group. SMART Recovery, or the Self-Management and Recovery Training program, is group-based and uses professional clinicians to facilitate discussion and foster mutual support for a range of addictive behaviours, alongside Cognitive Behavioural Therapy and Motivational Interviewing techniques. This paper reports on the qualitative component of this study and how participants perceive ROMs, and the potential shift to technological resources. Twenty semi-structured telephone interviews were conducted with participants from SMART Recovery groups across New South Wales, Australia. Participants discussed their use of mutual support within group meetings to manage their recovery, including: naming their goals in front of peers; learning from clinicians and group discussion; and developing reciprocal and caring relationships. They also described any previous experience with routine outcomes measures and how digital technologies might enhance or hinder group function. Participants valued mutual support groups and reported that digital technologies could be complementary to physical, weekly group meetings. They were also concerned that the introduction of technological resources might pose a threat to physical meetings, thereby risking their access to mutual support. Findings have implications for the implementation of ROM when delivered via digital mechanisms, and indicate threats and opportunities that warrant consideration for future initiatives.

Key words: SMART Recovery; Routine Outcome Monitoring; Mutual Support; Qualitative; mHealth; Addiction 
Introduction

Mutual support between clients in groups is a key component of group work practice and deliberately fostered by professionals to develop participants' commonality and engagement in therapeutic and behaviour change programs ${ }^{12}$. The benefits of mutual support groups for managing problematic alcohol and other drug (AOD) use are also widely documented ${ }^{3-5}$. Indeed, they are the most commonly accessed form of AOD treatment in the world ${ }^{6}$. Located within formal services, or externally within the community, mutual support groups run concurrently with interventions, such as residential rehabilitation, or on their own, and provide continuing care upon treatment cessation or completion ${ }^{7}$. Within AOD, 12-step programs such as Alcoholics Anonymous are the longest running form of mutual support group ${ }^{8}$, and much of the research evidence is derived from this approach ${ }^{9}$. The SelfManagement and Recovery Training program ("SMART Recovery") has received less attention by researchers and evaluators ${ }^{10}$. Developed as an alternative to 12-step approaches, SMART Recovery incorporates both motivational interviewing and cognitive behavioral therapy (CBT) to promote positive behavioral change for a range of addictive behaviors (Horvath, 2000; Horvath, 2012). The groups aim to help people to: (1) identify the relationship between thoughts, feelings and behaviours; (2) challenge unhelpful thoughts and beliefs; (3) utilise positive behavioral strategies; and (4) undertake homework activities between sessions (also referred to as 7-day action plans in SMART Recovery). Another major distinction between SMART Recovery and 12-step groups is that a facilitator leads each SMART Recovery group. The facilitator may be a professional or non-professional person, who has completed training in the SMART Recovery approach (Kelly, 2015; Kelly, 2016). SMART Recovery avoids presenting "addiction" as a "disease", and provides a forum for service users who do not wish to engage with the spiritual aspects of the 12-Step Movement ${ }^{12}$. SMART Recovery groups are widely available with over 300 SMART 
Recovery groups running throughout Australia, and over 3000 SMART Recovery groups worldwide ${ }^{13}$. In light of their widespread use, and the current paucity of research evidence ${ }^{10}$, improved understanding of the experience and outcomes of SMART Recovery participants is an important priority.

Evaluations of mutual support groups have been hampered by the absence of standardised outcomes measures within such settings. Routine Outcome Monitoring (ROM), or the regular, systematic, assessment of treatment outcomes ${ }^{14}$ allows organisations to understand, evaluate and improve service delivery ${ }^{15}$. Historically, ROM has relied on clinician ratings of progress ${ }^{14}$ and, in the vast majority of approaches, it is the clinician rather than the client ${ }^{16}{ }^{17}$ who is provided with information about treatment progress ('feedback'). Putting the client at the centre of the assessment ${ }^{18}$ and feedback ${ }^{19}{ }^{20}$ process is both consistent with the tenets of mutual support, and an important clinical and research priority. An opportunity exists to harness technology for this purpose.

One such technology is smartphones. The ubiquitous nature of smartphones ${ }^{21}$ and their functional capabilities of mobile health (mHealth ${ }^{22}$ ) applications (“apps”) make them ideal for the purposes of ROM and feedback. mHealth apps offer a quick, easy, interactive and engaging platform for tracking and accessing information about health and health-related behaviours ${ }^{23}$. Accessed via smartphones, mHealth apps have the added benefit of real-time engagement in everyday situations and offering moment-to-moment, tailored content and support as needed ${ }^{24}$. However, the uptake and sustained use of smartphone tools (e.g., SMS) in populations in treatment for substance use disorders has not always been high (e.g. ${ }^{25}$ ). Engagement with mHealth apps seems to be optimised when development is informed by an in-depth understanding of the end-user ${ }^{26}$. We therefore conducted a qualitative examination 
with SMART Recovery participants to inform the development of a purpose built mHealth app for ROM and tailored feedback.

The measures, and implementation of these, within any app need to be sensitive to the key processes of the SMART approach which includes self-determined goals, mutual support and the involvement of a trained facilitator ${ }^{827}$. As with other facilitated group work practice, mutual support is an intentional part of formal treatment programs. This is due to the benefits experienced by participants, which emanate from input by equals who have lived experience of their issues ${ }^{28}$. The effectiveness of mutual support requires further study, but previous reports are encouraging with service users experiencing positive outcomes for their primary concern, as well as a range of benefits in their social and health domains ${ }^{3}$. This study aimed to elicit participant views on using a novel, purpose built digital platform for routine outcome monitoring (ROM) as a standard component of a mutual support group. In what follows, we describe these views which seemed to further highlight the importance of mutual support between participants and how this influenced their perceptions of collecting ROMS via technological mechanisms.

\section{Methods}

Semi structured telephone interviews were audio recorded with the participants' permission. Interviews were 45 minutes on average, ranging from 20 to 90 minutes. Recordings were transcribed verbatim, checked for accuracy, and then de-identified. Pseudonyms replace names throughout. Approval for the conduct of the study was provided by the University of Wollongong and Illawarra Shoalhaven Local Health District (ISLHD) Health and Medical Human Research Ethics Committee (2018/099; HREC/18/WGONG/34).

\section{Participants}


Twenty participants (see Figure One) were recruited from SMART Recovery groups held across the Australian state of New South Wales (NSW). Sites include a range of geographical locations, service providers and settings (i.e. NSW Health districts, not-forprofit organisations, community-controlled health services and community/ volunteer run groups). SMART Recovery facilitators distributed research invitations and interested members were directed to the research team who provided them with comprehensive information about the study, including consent procedures and any risks and advantages to taking part. Those still interested were booked for a telephone interview at a time and date convenient to them. Following consent, demographic details were collected, and their first name and phone number was forwarded to the interviewer. Participants were reimbursed for their time with a supermarket voucher (\$30 AUD).

\section{Interview procedure}

Interviews were guided by a schedule which asked participants about: their aims for attending group meetings; the outcomes and impact of their attendance, if any; their knowledge, awareness and experience in routine outcomes; any experience using technology to monitor their progress; topics that would be useful to track; their knowledge, awareness and experience of doing these online; what might get in the way of collecting outcomes data; their perceptions on the role of the facilitator in this process; what advice they could give researchers in the development of the tools; and, finally, any final conclusions they feel are important to consider. The interview schedule was developed through a collaborative and iterative process. Informed by a review of the literature and then through discussion within the multidisciplinary team which included researchers with extensive experience in: using qualitative methods; conducting research on alcohol and other drug use; and applied research for clinical settings. Participants also reflected on the benefits and limits of the SMART Recovery process more generally, and we invited them to describe what works and their 
therapeutic preferences. At the closing stage, participants were also invited to discuss issues they viewed as pertinent.

Analysis

A combination of inductive and deductive methods was used, informed by the five stage process outlined by Braun and Clarke ${ }^{29}$. The first author developed a draft coding frame, which reflected the interview schedule and the key research aims, and sought feedback from the wider research team. The preliminary coding frame was trialled with a subset of transcripts, and a small number of inductive codes were added. The revised frame was presented to the team and discussed until consensus was reached, before the first author applied the final coding frame to the entire data set. The coding reports were reviewed in detail to generate a set of themes and sub-themes, and summaries of these were discussed among the broader research team to check for salience and relevance. This paper presents findings emanating from analysis of the coding reports labelled: benefits of SMART; mutual support; outcomes and impact; barriers to implementing ROMs; and, participant recommendations.

Results

Participant profile

Twenty participants (see Table 1) were interviewed over the course of six months, between April and October 2018. Participants ranged in age from 27 to $65(\mathrm{M}=46.3$, $\mathrm{SD}=9.91)$ and most identified as male $(\mathrm{n}=16)$. The majority of the participants were attending SMART Recovery for alcohol (40\%) or other drugs (35\%; see Table 1). They were living in a wide range of locations throughout New South Wales, in urban, regional and remote settings. In some instances, participants travelled up to two hours to access SMART 
Recovery meetings. Throughout the interviews, participants volunteered information about their mental health status. We note that the majority of participants were accessing formal psychological and/or psychiatric support, with many participants having been referred to SMART Recovery groups by their mental health professional. While the interview schedule included questions about the program, and mutual support is an integral element of this, it did not include questions about mutual support directly. It is interesting that mutual support was raised by participants and described passionately and frequently. Through these descriptions, participants describe the important role that other participants play in their AOD treatment process. Perhaps not surprisingly, then, their consideration of ROM, and the introduction of digital technologies, was viewed within this frame. First, we focus on the role of mutual support within SMART Recovery, which contextualises findings about mutual support and outcome measures, in the digital era. The implications of these findings will then be discussed.

\section{Mutual support at SMART Recovery group meetings}

Participants seemed to value the facilitated discussions fostered by clinicians, which enabled them to reflect on their past week, what had worked, and what they needed to further improve. Indeed, discussion at group meetings was described as a key tool in their efforts to reduce or abstain from problematic alcohol and other drug use. They described listening to "others in the same situation" and Juno (regional NSW) had what she called "aha moments". Seamus (regional NSW) described this as getting "a wake-up call" when realising "that could be me." The group meetings also seem to enable them to "strengthen their aims by verbalising them". Rhonda (regional NSW), for example, gained "support and touches base." Having their aims witnessed by their peers was thought to foster greater "accountability" and "authenticity" in their recovery. "Once you get out there and you learn from others and you

finally verbalise what your plans are, they become a bit stronger," (Broderick, regional 
NSW). When Malcolm (regional NSW) was asked about his aims in the SMART Recovery program, he said:

One is obviously to maintain my sobriety, I hate that word, but... That's goal number one. Goal number two is to get out of my head and on my feet so it's also a form of resocialisation. Three is to actually learn from others. And four, it's actually to share my experiences and things that have been successful for me and even the things that haven't been so helpful and provide my insight to others, so basically, we're giving back.

Malcom's interview highlights the multifactorial nature of mutual support which includes 'resocialisation' and 'learning from others' but also the benefits he gains in sharing what he has learnt, and helping other participants. Other participants also described sharing tools and experiences, both for their own learning, which is thought to increase their skills in managing AOD use through consolidating and integrating knowledge, and to share this knowledge, which seems to increase their self-esteem. For Jeremy (regional NSW), the groups:

Aim to do several things: to communicate and pass onto the participants tools and techniques for them to use; for them to participate and share with other people what they have experienced; and what they ... and the other way around for them to gain experience from what other peoples' experiences are; and ideas and what works for other people.

More than simply knowledge transfer, then, participants seemed to value the relational dynamic of learning and sharing, and overt forms of caring for other participants, "You get to know them in a group way $[. .$.$] you don't have a personal relationship with them, but you$ care about their story, you care about their journey and recovery" (Jeremy, regional NSW). For Malcolm (regional NSW), the "opposite of addiction is connection." Interviews were 
replete with descriptions of the caring communities that were fostered through meetings and that simply being there and listening to others' accounts of their challenges and progress was understood to be an important factor for their recovery. Physical groups seem to provide a forum through which participants gain company, reduce isolation, receive feedback and a sense that they are seen and heard. Bryn (rural NSW) also enjoyed the feeling of care and consideration for other people in these group meetings, and was passionate about the mutual support he was gaining from attendance at these groups, "It lifts you up and makes you pull that ... helps you pull that wall down in front of you, stops you from being isolated." Using the groups as a mechanism to counteract social isolation was a common thread in these interviews. Indeed, participants seeing a psychologist were referred to the group to "prevent me from isolating myself [...] I go there for support plus it gets me out of the house" (Barry, rural NSW).

For those directed or mandated to attend due to criminal law or family matters, attendance was originally to "just tick a box" or "get a stamp". While initially attending under duress, these participants described continuing with the program due to the mutual benefits they were experiencing. Some received what they called a "wake-up call" from veteran group participants or enjoyed "meeting others in the same boat.” Rex (regional NSW) described his shift in motivation, saying, "Yeah, my lawyer said if you do this it will help you, so I was like 'alright!' and so I went and then I started to attend all the time’”. Mutual support, which is fostered through weekly group meetings, seems to enable the sharing of knowledge and experience. It also provides these participants with opportunities to care, and feel cared for, and to witness the challenges of others. Where social isolation was thought to be a determinant to their problematic AOD use, these relationships provide opportunities for connection. For those attending to meet orders, the mutual support witnessed in group meetings was described as a motivation to keep attending. In the next section, we explore 
participants' perceptions of the introduction of routine outcome measures via digital platforms and the implications this has for them and their meetings.

Mutual support and outcomes measures, in the digital era

In terms of routine outcome measures, it was rare that participants had knowledge of these. It was common for them to say they had "never used them" or had "not heard of them" and inspired questions like, "What is that?" Participants described their use of paper-journals to track their progress and monitor their activities and lapses, with the hope that they could better see their trigger points and pre-empt them, or to see when they are making good progress which gives them "a boost". Jeremy (regional NSW) said "I keep a daily diary [...] I try to track really significant dealings of depression or anything like that $[\ldots]$ or more importantly non-drinking days, what groups I went to." Participants seemed to value the opportunity to witness their own progress. At times, this was viewed as potentially motivating as it enables participants to see their incremental changes, however gradual:

You know, if you're not going through a good time in life, sometimes you can get negative about everything, but here you would have something objective to look at, measurements or whatever, and you can sort of say: well this is good and I'm going to keep doing it (Shane, rural NSW)

Therefore, participants seem to be tracking their progress but not currently using mHealth apps to do this. Participants also raised the "7 day plan" and at times considered the applicability of this within a digital platform. A structured part of the weekly SMART Recovery meeting, the 7 Day Plan enables participants to plan for the coming week and focuses on predicting triggers that might lead to a lapse, and generate strategies to prevent this. Brenda (rural NSW) likes to use the 7-day plan to "reset for the next 7 days." 
Participants also value this tool as a source of information that enables reflection and revision within meetings:

[Integrating routine outcome measures into meetings would] be amazing. So instead of people trying to reflect on their last seven days and not really having an idea, they could be really specific around it as well [...] using this might spark more conversation (Clint, rural NSW)

Indeed, Malcolm (regional NSW) was already using his phone in this way, "I make notes in my phone at the end of the meeting so I have a record". Similarly, Rhonda (regional NSW) attends meetings to gain "a way forward for the next seven days, [...] I get a lot out of that, I get a lot out of the planning and it keeps me accountable to myself”' (Rhonda, regional NSW). Other participants described the ways this planning has been beneficial to them, and how planning, progress and measuring outcomes intersect:

The first time I went [...] we had this open discussion about whether like... what I thought of as too many beers and what was a realistic number, and then all of a sudden I had a plan for the following days and to go home and try a few things I'd not thought of [...] and that is the sort of main aim for SMART, it's very personally ascribed. (Seamus, regional NSW)

I have it there as a record and you can see how every...it's a way of saying: 'I haven't been doing too badly' [...] a way of seeing changes and patterns, and changes that I should be concerned about. (Jeremy, regional NSW)

While participants described ROM (or their interpretation of outcome measures) as a good fit for the SMART program, there were also reservations expressed. These related to concerns about breaches in confidentiality and privacy; that adopting the technological mechanisms 
would be too challenging; or that technological advances would not complement the group meetings, but hinder them or potentially lead to their cessation. For example, Malcolm (regional NSW) and Jeremy (regional NSW) like their notes and journals, as they cannot be accessed by other people. Jeremy (regional NSW) also expressed concerns that digital mechanisms might include intrusions, such as prompts or advertising, or that the information could be accessed by external parties. John had reservations about electronic tracking and feels his journal meets this need without the inherent privacy risks. He also hints at the ways in which group discussion is different from reporting privately within his journal:

What goes in my journal is sacred and recorded forever [...] and from my personal point of view. What goes in my journal is my business. I have to say that sometimes what I say in group is not entirely true, but what goes in my journal is entirely true.

For Jeremy (regional NSW) then, having a private space to be completely honest was thought to be complementary to his more witnessed therapeutic process within group meetings, and provides him a more authentic and reliable "metric" for him to use to ascertain needs and monitor his triggers.

For those less familiar with smart phone or tablet technology, the introduction of these resources was, unsurprisingly, met with trepidation. These were related to a lack of hardware or knowledge in how to use the technology in order to collect outcomes data. Participants tended to describe their need for younger relatives to teach them how to use these items, and in doing so highlight some potential training needs of this consumer group. Cillian (regional NSW) said that "older generations and people over 50" are unlikely to engage with digital platforms. There were also fears that technology would be used to replace face to face contact. Juno (regional NSW), for example, welcomed more resources, “as long as it doesn't negate the group, doesn't replace the group and the group options." Other participants, like 
Rhonda (regional NSW), expected participants who, “don't like to talk might use it [...] but not me, I'm not good on the phones [...] I need to voice things." For Enya (rural NSW), the program is "all about that connection and just showing up, you know?" Indeed, participants valued technological resources for their ability to increase participants' knowledge about upcoming group meetings. Broderick (regional NSW) said "it would be good if [digital resources] could keep you up to date on meetings," and Guy (regional NSW) would like "a locator, so your location and the nearest SMART [meeting].”

Attendance at group meetings, however sporadic, seems to signify a physical commitment to recovery, which is witnessed by fellow participants. Participants discussed their hope that digital resources will be used to maintain these meetings or help participants to "stay on track" through a recorded 7-day plan. While there were reservations about digital platforms being used in the SMART Recovery program, both for collection of ROM data and more broadly, participants saw the value in using technological resources. This was to enhance their recovery process through better tracking and to improve their access to groups through up-to-date meeting information provided in real time.

\section{Discussion}

This project aimed to generate data from SMART Recovery program users to inform the development of an associated mHealth app that would track client outcomes and provide a confidential forum through which they can record tailored feedback about their group. In doing so, we found that participants valued the mutual support fostered within weekly meetings, and that ROMs and the use of digital technologies were viewed with this priority in mind. As such, we recommend that other services and researchers wishing to implement mHealth apps within group program contexts, do so by factoring in these consumer preferences, and frame public facing information about the mHealth app accordingly. 
This paper provides support for findings of other published research about the important role that peers play in group work practice ${ }^{3} 30$ and the motivational and relational benefits of mutual support for participants of behaviour change groups. It also highlights the impactful nature of facilitated group work, compared to individual forms of therapy. Study participants described the ways in which SMART Recovery meetings provide opportunities for participants to connect with others facing similar challenges and develop mutual support networks with others who can understand their experiences. These opportunities were facilitated by clinicians, and participants valued what they learnt from peers and professionals, through dialogue, and to share what they have learnt with others. While valuing the clinician led interventions, facilitated exchanges by peers provided opportunities for overt forms of caring which seems to increase their self-esteem and reduce social isolation. For those not authentically engaged at the outset of the program, the mutual support witnessed at the meetings seemed to motivate continued attendance rather than just to fulfil externally imposed court orders. Some described 'wake up calls' from hearing others talk, in that peers shared the negative impact of problematic AOD use to their health and relationships, which seemed to enable participants to make new commitments to reducing the problematic nature of their AOD use and engage in more positive behaviours. The consideration of using routine outcome measures through an app was imbedded in these contextual issues and the preferences of these participants.

Therefore, this paper contributes to what is known about how SMART Recovery participants perceive their meetings, and the role that ROMs might play in the program. While participants were positive about the introduction of outcomes indicators, so they could track their progress to enhance their recovery, they were keen to add that these should not interfere with group process. It seems that the digital component of collecting this data raised some implications for them. Consistent with other research ${ }^{31}$ there were participants who 
were concerned that they would not have the access to digital hardware, or the competence to use it effectively. In some cases, there were concerns that the collection of data would negatively affect their privacy and confidentiality, or that elements of the SMART Recovery program would become intrusive, due to automated prompts. Ultimately, participants perceived outcomes measurements were in keeping with the SMART Recovery program, and that digital technologies could complement the group meetings, but not replace them. Given the importance that participants placed on mutual support, and physical attendance at weekly meetings, it is important for the implementation of ROM to be integrated in to meetings in ways to avoid disrupting group process. Moreover, providing information to participants about how information will be managed and used is also likely to dispel concerns some may have with confidentiality and data leaks.

The comprehensive and consistent collection of routine outcome measures for health and mental health interventions is notoriously low and/or slow in some countries ${ }^{32-37}$. Having said this, the collection of ROMS in Australia has been effective in some settings ${ }^{38}$. Digital technologies have been recommended to improve the collection of this data ${ }^{39}$, and this paper provides valuable client insights which can be used to guide the development and implementation of ROM as we have described participant concerns and preferences. A key finding is that ROM was viewed as particularly well suited to the SMART program, due to its emphasis on self-management and planning (i.e. the 7-day plans). The interviews, then, highlight opportunities for promoting mHealth and the digital collection of ROMs in ways that complement these goals: that is, a practical tool for them to use to better manage their recovery, in addition to the benefits of mutual support gained from group meetings. In doing so, it is more likely that participants will take part in the collection of routine outcome data. Future research would be advised to also track the role of facilitators when implementing ROMs and the extent to which they enhance or hinder digital data collection. Finally, we 
reiterate that these data underline the importance of mutual support to study participants, and that these participants tended to view new initiatives and opportunities within this frame.

Both evaluators and clinicians would be advised to consider this when designing and implementing routine outcome measurement via digital technologies, in this and comparable programs.

Conclusions

ROM was viewed by participants as complementary to the customisable and pragmatic nature of the SMART Recovery program, as long as the digital collection of this data does not affect their privacy or interfere with group process. Interviews with study participants support previous research findings about the value of mutual support among those underdoing a recovery process. It also contributes recent and local insights into participant perceptions of the role that group meetings play in this process.

\section{Role of funding}

This study was funded by the NSW Ministry of Health under the NSW Health Alcohol and Other Drugs Early Intervention Innovation Grant Scheme. The content is solely the responsibility of the authors and does not reflect the official views of the funding bodies.

\section{Contributors}

All authors made substantial contributions to study conception, design, conduct and/ or manuscript preparation. P.Kelly, Baker, Deane, Shakeshaft, Hides, Neale, J.Kelly, Beck, McGlaughlin and Argent secured funding. Gray conducted all study interviews and led on data analysis and manuscript preparation. Beck is trial coordinator, and in collaboration with P.Kelly oversaw recruitment, consent, enrolment and data collection procedures. Treloar oversaw study design, data analysis and manuscript preparation. All authors provided 
feedback on the study design, coding framework and proposed manuscript content. All authors offered critical revisions to the manuscript for important intellectual content, have approved the final version of this manuscript and agree to be accountable for all aspects of the work in ensuring that questions related to the accuracy or integrity of any part of the work are appropriately investigated and resolved.

\section{Conflict of Interest}

No financial conflict of interest exists. A/Prof P.Kelly, Prof Deane, Prof Baker, Prof Shakeshaft, Prof Hides, A/Prof Manning, Dr Larance, Dr Beck, A/Prof J. Kelly and Dr Argent all volunteer as members of the SMART Recovery Australia Research Advisory Committee. Ryan McGlaughlin is Executive Director of SMART Recovery Australia. Dr Argent is employed by SMART Recovery as the National Program Manager and Trainer.

\section{Acknowledgements}

This project is being implemented through a collaborative partnership between SMART Recovery Australia, and researchers at the University of Wollongong, University of Newcastle, University of New South Wales, University of Queensland, Monash University, Harvard University and King's College London. The research team gratefully acknowledge SMART Recovery facilitators for supporting recruitment, the time and expert insights from the members of our steering committee to the conduct of this research, and the valuable contributions made by SMART Recovery participants.

\section{References}

1. Gitterman A. Building Mutual Support in Groups. Social Work with Groups 1989;12(2):5-

21. doi: 10.1300/J009v12n02_02 
2. Gitterman A. Building Mutual Support in Groups. Social Work with Groups 2006;28(34):91-106. doi: 10.1300/J009v28n03_07

3. Tracy K, Wallace SP. Benefits of peer support groups in the treatment of addiction. Substance abuse and rehabilitation 2016;7:143-54. doi: 10.2147/SAR.S81535

4. National Institute for Health and Care Excellence. NICE Quality standard for drug use disorders. NICE quality standards QS23. London: National Institute in Health and Clinical Excellence, 2012.

5. National Institute for Health and Care Excellence. NICE: Alcohol-use disorders: diagnosis, assessment and management of harmful drinking and alcohol dependence. . London: National Institute for Clinical Excellence, 2011.

6. Dawson DA, Grant BF, Stinson FS, et al. Estimating the effect of help-seeking on achieving recovery from alcohol dependence. Addiction 2006;101(6):824-34. doi: 10.1111/j.1360-0443.2006.01433.x [published Online First: 2006/05/16]

7. Lubman DI, Manning V, Best D, et al. A study of patient pathways in alcohol and other drug treatment: Patient Pathways National Project. Fitzroy Melbourne Victoria: Turning Point Alcohol and Drug Centre, 2014.

8. Kelly JF, Yeterian JD. The role of mutual-help groups in extending the framework of treatment. Alcohol research \& health : the journal of the National Institute on Alcohol Abuse and Alcoholism 2011;33(4):350-55.

9. Kaskutas LA, Borkman TJ, Laudet A, et al. Elements that define recovery: the experiential perspective. Journal of studies on alcohol and drugs 2014;75(6):999-1010.

10. Beck AK, Forbes E, Baker AL, et al. Systematic review of SMART Recovery: Outcomes, process variables, and implications for research. Psychology of Addictive Behaviours 2017;31(1):1-20. doi: 10.1037/adb0000237 [published Online First: 2017/02/07] 
11. Kelly PJ, Raftery D, Deane FP, et al. From both sides: Participant and facilitator perceptions of SMART Recovery groups. Drug and Alcohol Review 2017;36(3):32532. doi: 10.1111/dar.12416 [published Online First: 2016/06/02]

12. Horvath AT, Sokoloff J. Individuals seeking non-12-step recovery. In: Lawson GW, Lawson AW, eds. Alcoholism \& Substance Abuse in Diverse Populations. 2nd edition ed. Austin: PRO-ED 2011:75-90.

13. Smart Recovery International. About Us 2019 [Available from: https://www.smartrecoveryinternational.org/ accessed 3rd April 2019.

14. Carlier IV, A van Eeden W. Routine Outcome Monitoring in Mental Health Care and Particularly in Addiction Treatment: Evidence-Based Clinical and Research Recommendations. Journal of Addiction Research \& Therapy 2017;08 doi: $10.4172 / 2155-6105.1000332$

15. Boswell JF, Constantino MJ, Kraus DR, et al. The Expanding Relevance of Routinely Collected Outcome Data for Mental Health Care Decision Making. Administration and Policy in Mental Health and Mental Health Services Research 2016;43(4):48291. doi: 10.1007/s10488-015-0649-6 [published Online First: 2015/04/12]

16. Davidson K, Perry A, Bell L. Would continuous feedback of patient's clinical outcomes to practitioners improve NHS psychological therapy services? Critical analysis and assessment of quality of existing studies. Psychology and Psychotherapy: Theory, Research and Practice 2015;88(1):21-37. doi: 10.1111/papt.12032 [published Online First: 2014/05/23]

17. Gondek D, Edbrooke-Childs J, Fink E, et al. Feedback from Outcome Measures and Treatment Effectiveness, Treatment Efficiency, and Collaborative Practice: A Systematic Review. Administration and Policy in Mental Health and Mental Health Services Research 2016;43(3):325-43. doi: 10.1007/s10488-015-0710-5 
18. Patient Reported Measures Team. Patient Reported Measures - Program Overview. Chatswood: NSW Agency for Clinical Innovation, 2018.

19. Carlier IV, Meuldijk D, Van Vliet IM, et al. Routine outcome monitoring and feedback on physical or mental health status: evidence and theory. Journal of Evaluation in Clinical Practice 2012;18(1):104-10. doi: 10.1111/j.1365-2753.2010.01543.x [published Online First: 2010/09/18]

20. Lambert MJ, Whipple JL, Kleinstauber M. Collecting and Delivering Progress Feedback: A Meta-Analysis of Routine Outcome Monitoring. Psychotherapy 2018;55(4):520-37.

21. Drumm JW, N. Morne, S. \& Davey, M. Mobile Consumer Survey 2017: The Australian cut - Smart everything, everywhere. Sydney: Deloitte, 2017.

22. Agarwal S, LeFevre AE, Lee J, et al. Guidelines for reporting of health interventions using mobile phones: mobile health (mHealth) evidence reporting and assessment (mERA) checklist. $B M J$ 2016;352 doi: 10.1136/bmj.i1174

23. Boudreaux ED, Waring ME, Hayes RB, et al. Evaluating and selecting mobile health apps: strategies for healthcare providers and healthcare organizations. Translational behavioral medicine 2014;4(4):363-71. doi: 10.1007/s13142-014-0293-9 [published Online First: 2014/09/24]

24. Garnett C, Crane D, West R, et al. Identification of Behavior Change Techniques and Engagement Strategies to Design a Smartphone App to Reduce Alcohol Consumption Using a Formal Consensus Method. JMIR mHealth and uHealth 2015;3(2):e73. doi: 10.2196/mhealth.3895

25. E. Taylor H, Deane F, Russell B. Feasibility of Using Short Message Service (SMS) to Collect Outcome Data in an Australian Residential Alcohol and Drug Treatment Service2017. 
26. Yardley L, Morrison L, Bradbury K, et al. The Person-Based Approach to Intervention Development: Application to Digital Health-Related Behavior Change Interventions. Journal of Medical Internet Research 2015;17(1):e30. doi: 10.2196/jmir.4055

27. Horvath AT, Yeterian J. SMART Recovery: Self-Empowering, Science-Based Addiction Recovery Support. Journal of Groups in Addiction \& Recovery 2012;7(2-4):102-17. doi: 10.1080/1556035X.2012.705651

28. Barker SL, Maguire N. Experts by experience: Peer support and its use with the homeless. Community Mental Health Journal 2017;53(5):598-612. doi: $10.1007 / \mathrm{s} 10597-017-0102-2$

29. Braun V, Clarke V. Using thematic analysis in psychology. Qualitative Research in Psychology 2006;3(2):77-101. doi: 10.1191/1478088706qp063oa

30. Gray R, Lewis P, Mokany T, et al. Peer Discussion and Client Motivation in Men's Domestic Violence Programs: An Australian Qualitative Interview Study. Australian Social Work 2014;67(3):390-404. doi: 10.1080/0312407X.2013.853196

31. Knight K, Hunter C. Paper 17: Using technology in service delivery to families, children and young people: Australian Institute of Family Studies, 2013.

32. Roe D, Gelkopf M, Gornemann MI, et al. Implementing routine outcome measurement in psychiatric rehabilitation services in Israel. International Review of Psychiatry 2015;27(4):345-53. doi: 10.3109/09540261.2015.1025722

33. Macdonald AJ, Fugard AJ. Routine mental health outcome measurement in the UK. International Review of Psychiatry 2015;27(4):306-19. doi: 10.3109/09540261.2015.1015505 [published Online First: 2015/04/03]

34. Kisely S, Adair CE, Lin E, et al. Routine outcome measures in Canada. International Review of Psychiatry 2015;27(4):286-95. doi: 10.3109/09540261.2014.994594 [published Online First: 2015/03/05] 
35. Puschner B, Becker T, Bauer S. Routine outcome measures in Germany. International Review of Psychiatry 2015;27(4):329-37. doi: 10.3109/09540261.2015.1014025

36. Ruud T. Routine outcome measures in Norway: Only partly implemented. International Review of Psychiatry 2015;27(4):338-44. [published Online First: 2015/08/11]

37. Goldman HH, Seybolt D. What can we learn from the ongoing challenge to implement routine outcome measures? Int Rev Psychiatry 2015;27(4):261-3. [published Online First: 2015/08/06]

38. Burgess P, Pirkis J, Coombs T. Routine outcome measurement in Australia. International Review of Psychiatry 2015;27(4):264-75. doi: 10.3109/09540261.2014.977234 [published Online First: 2015/03/15]

39. Delespaul PA. Routine outcome measurement in the Netherlands - A focus on benchmarking. International Review of Psychiatry 2015;27(4):320-8. doi: 10.3109/09540261.2015.1045408 [published Online First: 2015/06/25] 
Table 1.

SMART Recovery Group Participant Characteristics

\begin{tabular}{|c|c|}
\hline Gender (\%Female) & $20 \%$ \\
\hline Age & $\begin{array}{l}M=46.30(S D=9.91) \\
\text { Range }=27-65\end{array}$ \\
\hline Country of birth (\% Australia) & $75 \%$ \\
\hline Ethnicity (\% Aboriginal or Torres Strait Islander) & $0 \%$ \\
\hline Highest level of education or training & \\
\hline University - Postgraduate degree & $15 \%$ \\
\hline University - Bachelor degree & $15 \%$ \\
\hline Certificate, Diploma and/ or Trade & $45 \%$ \\
\hline High School or Less & $24 \%$ \\
\hline Frequency of group attendance & \\
\hline Once a month & $5 \%$ \\
\hline 2 to 3 times per month & $20 \%$ \\
\hline Once a week & $55 \%$ \\
\hline 2 times a week & $20 \%$ \\
\hline Duration of group attendance (months) & $\begin{array}{l}M=56.95(S D= \\
45.31) \\
\text { Range = One week to } \\
12 \text { years }\end{array}$ \\
\hline Main reason for attending SMART Recovery & \\
\hline Alcohol & $40 \%$ \\
\hline Drugs & $35 \%$ \\
\hline
\end{tabular}


Other 


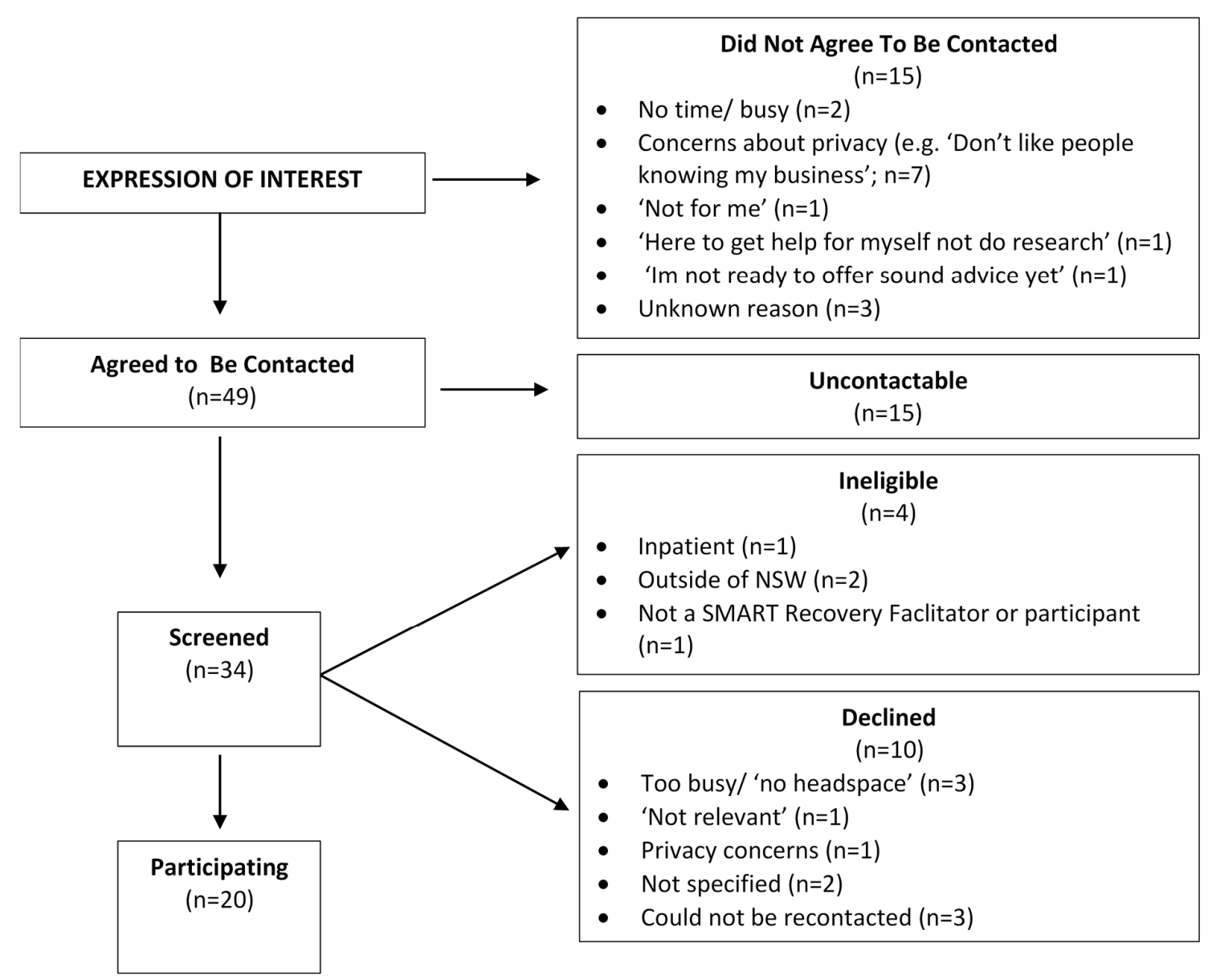

Figure X. Recruitment Consort Diagram 
